\title{
Comparison of the outcome of management of congenital idiopathic clubfoot treated by ponseti method with modified technique

\author{
MM Newaz ${ }^{1}$, AK Sikder ${ }^{2}$, Faruquzzaman ${ }^{3}$
}

\begin{abstract}
Background: Ponseti's technique has become the standard and most effective treatment modality for correction of Congenital Talipes Equinovarus (CTEV) in newborn. With time, little modification has been done in the classic technique.

Objective: Our objective in this study was to compare the outcome in the recent years (modified Ponseti technique) with the results of our previous study (classic Ponseti technique).

Methods: A total number of 976 patients (1553 feet) of Congenital Talipes Equino Varus were treated from October 2009 to February 2019 in Khulna Medical College Hospital and in private hospitals. In this retrospective study (based on convenient sampling), there were two groups. In group A, a total 621 patients (with a total 1033 feet) were treated from October 2009 to August, 2015. In group B, 355 patients (520 feet) were treated from November 2015 to February 2019.

Results: In this study, in group A, approximately 88.6\% was in 0-6 months age group. $64.9 \%$ was male patients. $3.7 \%$ patients had positive family history. In group $B$, majority of the patients $(301,84.8 \%)$ was in $0-6$ months age group. 211 patients (59.4\%) was male child. In approximately $3.1 \%$ (11) patients family history was positive. Approximately in 95.9\% (991 out of total 1033) and 96.5\% (502 out of total 520) feet respectively in group $A$ and $B$, tenotomy was required. Dropout rates were $7.6 \%$ and $4.1 \%$ in respective groups. Minor bleeding was observed in approximately $1.5 \%$ (15) and $1.4 \%$ (7) feet in respective groups, followed by plaster related complications in approximately $2.2 \%$ (23) and $1.0 \%$ (5) feet in group $A$ and B. Patients' compliance was found significantly higher in group $B$ in contrast to group $A$. In group $B$, it was over 90\%, whereas in group $A$, it was approximately $64.1 \%$.
\end{abstract}

Conclusion: The ultimate outcome of Ponseti repair is improving by less requirement of total number of plaster, resistant cases and reduction in overall dropout rate by the newer modification.

Keywords: Percutaneous needle tenotomy, Ponseti method, Congenital talipes equinovarus.

\section{Introduction}

The Ponseti method of treatment for congenital clubfoot has gained widespread clinical acceptance. In the last 2 decades, it is considered as the best conservative way to address this complex deformity. ${ }^{1}$ One report on the long term outcome of the Ponseti method particularly inspired pediatric orthopaedic surgeons to adopt this treatment. ${ }^{2}$ The authors reported in detail on the simplicity of the method to achieve and maintain a flexible, planti-grade, and painless foot. However, because there are insufficient data

on the worldwide use of different methods for clubfoot management, one could assume numerous centers still treat congenital clubfoot by initial casting followed by surgical correction of residual deformities. Outcome of treatment is rated differently in the literature with some authors presenting success rates of as much as $80 \%$ excellent or good short to midterm outcomes for Ponseti management and for surgical treatment. $^{2}$ In light of seemingly comparable outcomes, the much less invasive

1. Md Mehedi Newaz MS, Associate Professor, Dept. of Orthopaedics, Khulna Medical College. (E-mail: drmehedinewaz@yahoo.com)

2. Avijit Kumar Sikder D.Ortho, Resident Surgeon (Orthopaedics), Khulna Medical College Hospital.

3. Faruquzzaman MS, Assistant Registrar, Department of Surgery, Khulna Medical College Hospital. 
treatment pioneered by Ignacio V. Ponseti is repeatedly cited as the preferred treatment. ${ }^{3-5}$ The evidence to support this estimation is based on retrospective trials and a few studies with historical control groups.6,7 Larger groups of patients with follow up have been reported only by a couple of centers worldwide. ${ }^{4}$ For almost 3 decades, we treated congenital clubfoot with manipulation (following the guidelines of Johann Bosch from the 1950s, whose approach was remarkably similar to that of Ponseti) and casting up to the age of 6 months followed by posteromedial release. 8

The less invasive character, the straight forward biomechanical concepts, and the favorable reports on the Ponseti method motivated us to organize a prospective study in 2015 to evaluate the outcome in common orthopaedics practice in 2015.9 Thereafter, some modification of Ponseti technique has been introduced, such as introduction of minimal invasive percutaneous needle tenotomy. This ultimately improved patients' compliance over time. Moreover with time, our experience and expertise also became more refined and we were expecting a better outcome than our previous study. Now in this current study, our objective was to compare the outcome in the past recent years (modified technique) with the results of our previous study (classic technique).

\section{Materials and Methods}

A total number of 976 patients (1553 feet) of Congenital Talipes Equino Varus were treated from October, 2009 to February 2019 on an outpatient basis in Khulna Medical College Hospital and in private hospitals. This study was conducted retrospectively in two groups. In group A, a total 621 patients (with a total 1033 feet) were treated from October, 2009 to August, 2015 (in our previous study classic Ponseti technique). On the other hand, in group B, 355 patients (520 feet) were treated from November 2015 to February 2019 (modified Ponseti technique). In modified technique blade tenotomy is replaced by percutaneous needle tenotomy which is simpler and apparently safer. All data was collected and analyzed retrospectively. Convenient purposive sampling was used as a method of selecting sample on the basis of inclusion and exclusion criteria. In this clinical study, both manual and computer based statistical analysis of the data were done. Data were analyzed manually and then rechecked with SPSS (Statistic package for social science) computer package programme. The survey data were analyzed using both analytic as well as descriptive statistic. Such as; mean, SD, percentage, $\mathrm{p}$ value (where appropriate). Ethical clearance is taken individually from patient and from the ethical review committee of Khulna Medical College Hospital.

\section{Results}

The demographic profile of the study population in group A (621 patients with a total 1033 feet) and B (355 patients with 520 feet) is depicted in Table 1.

\section{Table I}

Demographic distribution of the study population in group A and B

\begin{tabular}{|c|c|c|c|}
\hline \multicolumn{4}{|c|}{ Group A } \\
\hline Variables & \multicolumn{2}{|r|}{ Number } & $\%$ \\
\hline \multirow[t]{2}{*}{ Age } & $0-6$ months & 550 & 88.6 \\
\hline & $>6$ months & 71 & 11.4 \\
\hline \multirow[t]{2}{*}{ Gender } & Male & 403 & 64.9 \\
\hline & Female & 218 & 35.1 \\
\hline \multirow{2}{*}{ Family history } & Positive & 23 & 3.7 \\
\hline & Negative & 598 & 96.3 \\
\hline \multirow{4}{*}{\multicolumn{2}{|c|}{$\begin{array}{l}\text { Average Pirani score at presentation } \\
\text { Average number of casts before tenotomy } \\
\text { Minimum duration of follow up } \\
\text { Average Pirani score at last follow up }\end{array}$}} & 4.3 & \\
\hline & & 4.7 & \\
\hline & & $12 \mathrm{Mc}$ & nths \\
\hline & & 4.5 & \\
\hline \multicolumn{4}{|c|}{ Group B } \\
\hline \multirow[t]{2}{*}{ Age } & $0-6$ months & 301 & 84.8 \\
\hline & $>6$ months & 54 & 15.2 \\
\hline \multirow[t]{2}{*}{ Gender } & Male & 211 & 59.4 \\
\hline & Female & 144 & 40.6 \\
\hline \multirow[t]{2}{*}{ Family history } & Positive & 11 & 3.1 \\
\hline & Negative & 344 & 96.1 \\
\hline \multicolumn{2}{|c|}{ Average Pirani score at presentation } & 4.1 & \\
\hline \multicolumn{2}{|c|}{ Average number of casts before tenotomy } & 5.2 & \\
\hline \multicolumn{2}{|c|}{ Minimum duration of follow up } & 2 Months & \\
\hline \multicolumn{2}{|c|}{ Average Pirani score at last follow up } & 4.4 & \\
\hline
\end{tabular}

Total number of plaster (on an average), resistant and treatment failure cases in both groups is represented in Table II.

\section{Table II}

Necessity of number of plasters in study population and outcome of cases

\begin{tabular}{lccccc}
\hline \multirow{2}{*}{ Indices } & $\begin{array}{c}\text { Total number of plaster } \\
\text { Up to 05 }\end{array}$ & $06-07$ & $08-09$ & $\mathrm{RC}$ & $\mathrm{TF}$ \\
\hline Number of patient (Gr. A) & 571 & 33 & 11 & 06 & 00 \\
$\%$ & 92.0 & 5.3 & 1.7 & 1.1 & 00 \\
Number of patient (Gr. B) & 338 & 11 & 05 & 01 & 00 \\
$\%$ & 95.2 & 3.1 & 1.4 & 0.3 & 00 \\
\hline
\end{tabular}

$\mathrm{RC}=$ Resistant cases after treatment, $\mathrm{TF}=$ Treatment failure cases 
Initially a total number of 672 cases were included in group A, but 51 were dropped out at different phases of treatment (previous study data), whereas, in group B, it were 370 and 15 respectively. Dropout rates were depicted in figure 1.

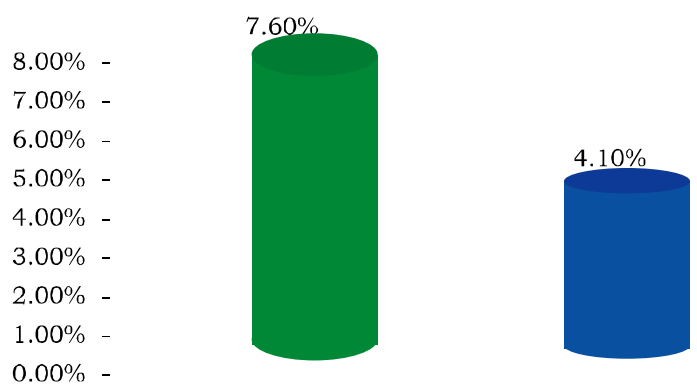

Figure 1. Dropout rate in both groups

In this study, total 1033 feet of clubfoot were treated within the study period in group A, among which in 991 (95.9\%) feet tenotomy was required in course of management. Total 520 feet of clubfoot were treated within the study period in group B, among which in 502 (96.5\%) feet needle tenotomy was required in course of management (figure 2).

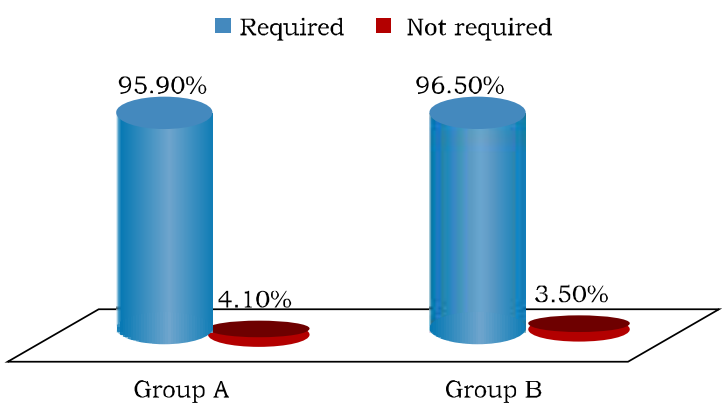

Figure 2. Rate of blade and needle tenotomy (in Group A and B respectively).

Among the 1033 and 502 feet treated in group A and B respectively, the rate of complications is presented in Table III.

Table III

Procedure related complications in both phases

\begin{tabular}{lccc}
\hline Complications & $\begin{array}{c}\mathrm{N}(\%)=1033 \\
\text { feet (Group A) }\end{array}$ & $\begin{array}{c}\mathrm{N}(\%)=502 \\
\text { feet (Group B) }\end{array}$ & P value* \\
\hline $\begin{array}{l}\text { Plaster related } \\
\text { complications }\end{array}$ & $23(2.20)$ & $05(1.0)$ & \\
Bleeding (Minor) & $15(1.5)$ & $07(1.4)$ & \\
Pseudo aneurysms & $00(00)$ & $00(00)$ & $>0.05$ \\
Neurovascular injuries & $11(1.1)$ & $01(0.2)$ & \\
Infection & $19(1.8)$ & $03(0.6)$ & \\
Incomplete tenotomy & $02(0.2)$ & $02(0.4)$ & \\
Loss of control over needle & $03(0.6)$ & \\
\hline
\end{tabular}

* P values are calculated using ANOVA overall patients' compliance in both groups is presented in figure 3 .

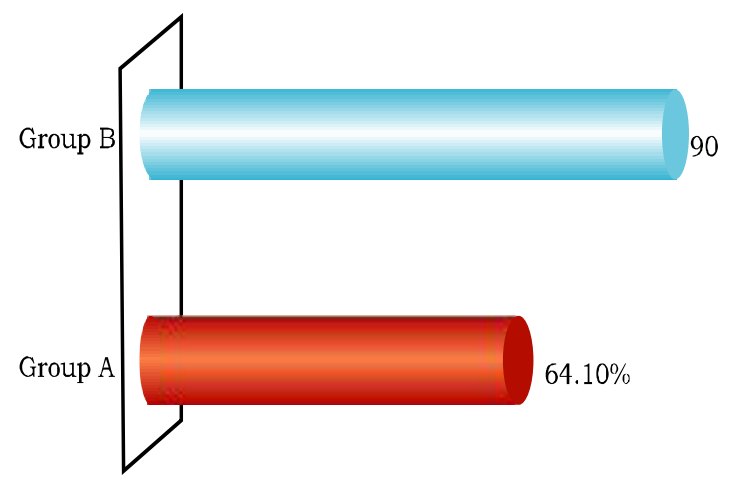

Figure 3. Patients' compliance in both groups

\section{Discussion}

In group $\mathrm{A}$, most of the patients, approximately $88.6 \%$ (550 patients) was in 0-6 months age group. $64.9 \%$ was male patients. $3.7 \%$ patients had positive family history. Average Pirani score at presentation was 4.3 in group A. Among the 355 cases in group $\mathrm{B}$, it has been found that majority of the patients $(301,84.8 \%)$ was in $0-6$ months age group and 211 patients $(59.4 \%)$ was male child. In approximately $3.1 \%$ (11) patients family history was positive. Average Pirani score before the initiation of treatment was 4.11. Average number of casts before tenotomy was 5.2. A minimum 12 months follow up was done in each patient. It has been observed that approximately in $95.9 \%$ (991 out of total 1033) and 96.5\% (502 out of total 520) feet respectively in group A and $\mathrm{B}$, tenotomy was required.

In our previous study, 9 it was found that among the patients in group A (approximately 92\%), only 05 serial plasters were found to be sufficient, whereas, only in $5.3 \%$ patients $06-07$ plasters were required followed by $1.7 \%$ patients requiring more than 07 plasters, whereas, in group $\mathrm{B}$, these were $95.2 \%, 3.1 \%$ and $1.4 \%$ respectively. 06 $(1.1 \%)$ resistant cases were found where correction was relatively slower than others, but no case of treatment failure was identified. In contrast, in case of group B, resistant case was only $0.3 \%$. Initially a total number of 672 cases were included in group A, but 51 were dropped out at different phases of treatment (previous study data), whereas, in group B, it were 370 and 15 respectively. Overall dropout rates were $7.6 \%$ and $4.1 \%$ in respective groups. Dropout rate tends to fall gradually. Procedure related complications is decreasing, patient party is educating. Ponseti technique is being more reliable method to the 
parents of the child with CTEV and thus dropout rate is decreasing.

Ponseti's technique' has become the standard and most effective treatment modality for correction of CTEV in newborn.10,11 It consists of weekly stretching plaster casts followed by percutaneous tenotomy of tendoachilles. Achilles tenotomy is needed in $70-80 \%$ of cases after successful correction of forefoot adduction and heel varus. ${ }^{12-}$ 13 Earlier, it was done by open method. This practice was later discontinued because of its invasiveness and relatively high rate of complications. Now a days, as a part of Ponseti's method, it is done percutaneously with a surgical blade (no. 11 and 15 being most commonly used). It is a simple and safe technique. However, with the increasing popularity of this procedure, complications are being reported.14,15 These usually consist of excessive bleeding, formation of pseudoaneurysm and neurovascular injuries. Several modifications of this technique which includes use of modified surgical blade designs and even mini open methods have been reported in an attempt to decrease these complications. ${ }^{16,17}$ Percutaneous tenotomy with a needle was described earlier in literature to correct trigger finger deformity. ${ }^{17}$ Minkowitz B et al., first described the use of a large gauge hypodermic needle to section the tendo Achilles percutaneously as a modification of Ponseti method.18 Thereafter, similar studies were published by different authors describing this modified technique. 19-22

In literature review, different studies have been found regarding the complications of percutaneous needle tenotomy. ${ }^{11-15}$ But in this study, no major complication has been documented. The results reflect that minor bleeding was observed in approximately $1.5 \%$ (15) and $1.4 \%(7)$ feet in respective groups, followed by plaster related complications in approximately in $2.2 \%(23)$ and $1.0 \%$ (5) feet in group A and B. Only 1 case $(0.2 \%)$ out of total 502 tenotomy was associated with neurovascular injury in group B, whereas in group $\mathrm{A}$, it was $1.1 \%$. Infection and incomplete tenotomy rate was found $0.6 \%$ and $0.4 \%$ respectively in group B. In contrast, in group $\mathrm{A}$, infection rate was approximately $1.8 \%$. P value reflects statistically less significant result here $(>0.05$, using ANOVA test). Another important finding of this study was patients' compliance which was found significantly higher in group B in contrast to group A. In group B, it was over $90 \%$, whereas in group A, it was approximately $64.1 \%$.
Possibly this better compliance in group B is due to several factors. With time, acceptance of Ponseti method is increasing day by day for its better outcome. This method is being more reliable and popular among the patient and guardians. If fact, initially complications were relatively high, therefore patients' compliance was less. And over time expertise and experience is increasing, complications are decreasing gradually. And thus patients' compliance is increasing rapidly.

A study was performed in Dhaka Medical College Hospital and published in 2014. In that particular study, it has been found that rate of procedure related bleeding was $2.85 \%$. Infection rate was found nil, whereas difficult procedure was observed in $5.71 \%$ of all cases. 22 In a study of Maranho DAC et al. abnormal bleeding was found as the major complication ( 2 cases out of 57 cases) in cases of needle tenotomy, whereas in another study, 15 difficult procedure was observed as the major problem (4 out of 70 cases). ${ }^{12}$ In most of the study, complications are claimed as nil with needle tenotomy. ${ }^{13,14}$ Another important issue is that most of the initial studies with the introduction of percutaneous tenotomy were at experimental stage. Thus with less experience and expertise, patient's compliance was less and complications were relatively high. Now with time, complications are expected and found to be less. A falling trend of procedure related complications is observed in this study in comparison with other studies.

This study limitation was conduction with a relatively limited number of study subjects over a shorter study period. Convenient sampling was used as the screening method to select the study population. Randomization and blinding was not done. Therefore, selection bias in this study couldn't be fully eliminated.

\section{Conclusion}

Ultimate outcome of Ponseti repair is improving by less requirement of total number of plaster, resistant cases and reduction in overall dropout rate. Currently, modified Ponseti repair is more resilient procedure in contrast to blade tenotomy in terms of complication rate and patients' compliance, along with low morbidity. Therefore, this modified technique of tendo Achilles tenotomy is recommended for treatment of idiopathic' club foot deformity in younger children as a part of Ponseti technique. 


\section{References:}

1. Ponseti IV. Congenital Clubfoot. Fundamentals of treatment. Ist ed. Oxford, United Kingdom: Oxford University Press Inc; 1996

2. Ponseti IV, et al. Treatment of the Complex Idiopathic Clubfoot. Clinical Orthopaedics and Related Research. 2006: 451: 171-176

3. Herzenberg JE, Radler C, Bor N. Ponseti versus traditional methods of caging for idiopathic clubfootJ Pediatr Orthop. 2002; 22: 517-521

4. Morcuende JA, Dolan LA, Dietz FR, Ponseti IV. Radical reduction in the rate of extensive correctivesurgery for clubfoot using the Ponseti method. Pediatrics. 2004; 113: 376-380

5. Scher DM. The Ponseti method for treatment ofcongenital club foot. Cunr Opin Pediatr. 2006. 18:22-25

6. Segev E, Keret D, Lokiec F, Yavor A, Wientroub S,Ezra E, Hayek S. Early experience with the Ponseti method for the treatment of congenital idiopathic clubfoot. Isr Med Assoc J. 2016; 7: 307310

7. Jppolito, E, Farsetti P, Caterini R, Tudisco C. Longterm comparative results in patients with congenital clubfoot treated with two different protocols. J Bone Joint Surg Am. 2003; 85: 12861294

8. Morcuende JA, Dolan LA, Dietz FR, Ponseti IV. Radical Reduction in the Rate of Extensive Corrective Surgery for Clubfoot Using the Ponseti Method. Pediatrics. February 2014; 113: 376-380

9. Newaz MM, Sikder AK, Outcome of management of congenital idiopathic clubfoot by ponseti technique, Bang Med J Khulna 2015; 48: 11-15

10. Goksan SB, Bursali A, Bilgili F, Sivacioglu S, Ayanoglu S. Ponseti technique for the correction of idiopathic clubfeet presenting up to I year of age. A preliminary study in children with untreated or complex deformities. Arch Orthop Trauma Surg. 2006; 126: 15-21

11. Scher DM, Feldman DS, Van Bosse HJP, Sala DA, Lehman". Predicting the need for tenotomy in the Ponseti method for correction of clubfeet. J Pediatr Orthop. 2004; 24: 349-52
12. Bor N, Coplan JA, Herzenberg JE. Ponseti treatment for idiopathic clubfoot: minimum 5 year follow up. ClinOrthop Relat Res. 2009; 467: 126370

13. Dobbs Nffl, Gordon JE, Walton T, Schoenecker PL. Bleeding complications following percutaneous tendoachilles tenotomy in the treatment of clubfoot deformity. J Pediatr Orthop. 2004; 24: 353-57

14. Burghardt RD, Herzenberg JE, Ranade A. Pseudoaneurysm after Ponsetipercutaneous Achilles tenotomy: a case report. J PediatrOrthop. 2008; 28: 366-69

15. Minkowitz B, Finkelstein BI, Bleicher M. Percutaneous tendo Achilles lengthening with a largegauge needle: a modification of the Ponseti technique for correction of idiopathic clubfoot. J Foot Ankle Surg. 2015; 43: 263-65

16. Dogan A, Kalender AM, Seramet E, Uslu M, Sebik A. Mini open technique for the achilles tenotomy in correction of idiopathic clubfoot: a report of 25 cases. J Am Podiatr Med Assoc. 2008; 98: 414-17

17. Rhett M, William H, Brian S, Garrett L. A mini open technique for Achilles tenotomy in infants with clubfoot. J Child Orthop. 2016; 10: 19-23

18. Saldana MJ. Trigger digits: diagnosis and treatment. J Am AcadOrthop Surg. 2001; 9: 246-52

19. Maranho, DAC, Nogueira Barbosa MK Simio MN, Volpon JB. Use of a large 16 gauge needle for percutaneous sectioning of the Achihes tendon in congenital clubfoot. Acta Ortop Bras. 2010; 18: 271-6.

20. Patwardhan S, Shyam A, Sancheti P. Percutaneous needle tenotorny for tendo achillis release in clubfoot technical note. J Orthop Case Rep. 2012; 2: $35-36$

21. Sirsikar A, Kiradiya N. A prospective study of outcome of percutaneous needle tenotomy for tendoachilles release in congenital talipes equiovarus. International Journal of Medical Science Research and Practice. 2014; 1: 84-88

22. Rahman MS, Alam. MK, Shahiduzzaman M, Rahman A. Percutaneous needle tenotomy for ponseti technique in the management of congenital talipes equinovarus (ctev). J Dhaka Med Coll. 2014; 23: 55-59 